\title{
MITO Y RITO DIONISÍACO EN BACANTES DE EURÍPIDES: SOBRE EL ORIGEN RITUAL DEL TEATRO
}

\author{
Juan Tobías Nápoli` \\ Centro de Estudios Helénicos-IdIHCS \\ Universidad Nacional de La Plata-CONICET
}

\begin{abstract}
RESUMO: No párodo de As Bacantes, de Eurípides, obra que tem sido descrita por unanimidade como a melhor representação do dionisismo grego e, por isso, do rito em cuja celebração se teria originado a tragédia clássica, o coro de mulheres asiáticas explica o que é o fundamento mítico de suas crenças e, ao mesmo tempo, descreve o tipo de rituais que praticam. A partir dessa dupla explicação, procuraremos analisar a passagem com duplo referencial, quanto à consideração desses rituais como um exemplo dos cultos que deram origem ao teatro clássico e quanto à interpretação geral da tragédia como uma reflexão sobre o fazer teatral por parte de seu autor.
\end{abstract}

PALAVRAS-CHAVE: Tragédia de Eurípides; Bacantes; párodo; espetáculo.

acantes, tragedia de Eurípides compuesta entre los años 408-406 a. C., fue representada de manera póstuma. Allí se presenta el momento en que el dios Dioniso, convertido en un profeta de su propio culto, llega hasta la griega ciudad de Tebas, para anunciarle a los familiares de su madre (entre ellos, el rey Penteo), que él es en realidad hijo de Zeus y, como tal, una divinidad. El rey se opone a estos nuevos cultos que quieren alejar a las mujeres del seno de la casa, e intenta apresar al profeta de esta religión nueva. El fracaso es estruendoso: no sólo que no puede detener el avance avasallador de las mujeres enloquecidas en

^juanapoli@hotmail.com 
el frenesí dionisíaco, sino que él mismo se convierte en víctima del sacrificio cultual por parte de su propia madre, quien desgarra su cuerpo y corta su cabeza como hacían las ménades báquicas con sus víctimas animales en el tramo final de sus celebraciones nocturnas en la montaña.

El mensaje final del poeta ha sido interpretado de manera absolutamente contradictoria: ¿quiere Eurípides denunciar a través de su tragedia los riesgos y peligros a los que conduce cualquier tipo de actitud religiosa (o, al menos, vinculada con el emocionalismo) ${ }^{1}$ o, por el contrario, está planteando una retractación de su anterior confianza en la fuerza de la razón, para volver a manifestar una encendida defensa de los valores vinculados con esta actitud religiosa o emocionalista? ${ }^{2} \mathrm{Se}$ trata del viejo debate entre racionalismo o irracionalismo en la interpretación de Eurípides. ¿Está el poeta por lo tanto a favor de Dioniso y lo que muestra en su tragedia es la incapacidad del racionalista Penteo para comprender los alcances y la significación de un aspecto de la realidad inasible para la razón o, por el contrario, el poeta está a favor de Penteo y, a través de su tragedia, intenta denunciar los peligros que entrañan las religiones orgiásticas y extáticas y el modo en que el hombre ilustrado debe convertirse en mártir de las emociones de las multitudes? Las dos respuestas se han formulado. También se han intentado los

\footnotetext{
${ }^{1}$ Es lo que opinan Verrall (Euripides, the Rationalist. A study in the history of art and in religion Cambridge: Cambridge University Press, 1895/ The Bacchants of Euripides and other essays. Cambridge: Cambridge University Press, 1910), Norwood (The riddle of the Bacchae. London: Victoria University of Manchester, 1908/ Essays on Euripidean drama. Berkeley: University of California Press, 1954), Nestle (Euripides. Der Dichter der griechischen Aufklärung. Stuttgart: W. Kohlhammer, 1901/Von Mythos zum Logos. Die Selbstentfaltung des griechischen Denkens von Homer bis aufdie Sophistik und Socrates. Stuttgart: Scientia, 1941/ Historia del espíritu griego. Barcelona: Ariel, 1987), Greenwood (Aspects of euripidean tragedy. New York: Cambridge at the University Press, 1972) y Murray [Eurípides y su tiempo. México: Fondo de Cultura Económica, 1966 (1913)].

${ }^{2}$ Es lo que opinan Gregoire (Euripide. Les Bacchantes. Paris: Les Belles Lettres, 1961. Tome VI), Jeanmaire (Dionysos. Paris: Payot, 1951), Lesky (Historia de la literatura griega. Madrid: Gredos, 1976), Roux (Euripide. Les Bacchantes. Introduction, texte et traduction, commentaire. Paris: Les Belles Lettres, 1970 y 1972), Festugière (De l'essence de la tragédie grecque. Paris: Aubier-Montaigne, 1969/Études de religion grecque et héllenistique. Paris: Vrin, 1972), Lacroix (Les Bacchantes d' Euripide. Paris: Les Belles Lettres, 1976) y Rivier [Essai sur le tragique d'Euripide. Lausanne: Rouge, 1944/ L'élément démonique chez Euripide. En: Diller, H.; Kamerbeek, J. C.; Lesky, A.; Martin, V.; Rivier, A.; Winnington-Ingram, R. P.; Zuntz, G. (orgs.). Euripide. Fondation Hardt pourl'étude de l'antiquité classique. Genève: Fondation Hardt, 1960. Tome VI, p. 43-86.]
} 
caminos intermedios. ${ }^{3}$ Por ello es que puede decirse, sin temor a caer en exageraciones, que se trata de una de las tragedias más polémicas de todos los tiempos, y su discusión representa no sólo un gran reto, sino que también permite plantear una serie de cuestiones teóricas acerca de las posibilidades de la interpretación filológica y hermenéutica de los textos clásicos. Intentaremos demostrar que en la párodos de Bacantes, Eurípides describe al mismo tiempo algunos aspectos vinculados con el culto dionisíaco y realiza una reflexión meta-discursiva acerca del género trágico. ${ }^{4}$

Para demostrarlo partiremos de un pasaje crucial del tercer episodio. Después que en el verso 810 el dios decide abandonar el intento de persuadir a Penteo acerca de la divinidad de Dionisos y de su derecho a recibir un culto público en Tebas, el cambio de estrategia del dios travestido en profeta de su culto tiene claras implicancias respecto del propio culto dionisíaco y respecto del teatro como género. Se trata del verso 815, en el que Dioniso, mientras trata ahora de persuadir a Penteo para que vaya a observar el culto de las mujeres sobre las laderas del monte, nos pone en presencia de un ejemplo de lo que se ha denominado la paradoja trágica, ${ }^{5}$ que consiste en el hecho de que el espectador de la tragedia encuentre placer en la contemplación del

${ }^{3}$ Es lo que han intentado, sobre todo, Dodds (The "Bacchae" of Euripides. London: Clarendon Press, 1968), Kauffmann (Tragedia y filosofía. Barcelona: Seix Barral, 1978), Jaeger (Paideia. Trad. de Joaquín Xiral. México: Fondo de Cultura Económica, 1967), Kirk (The "Bacchae" of Euripides. Prentice Hall: Englewood, 1970), Schmidt (Geschichte der griechischen Literatur. München: Beck, 1940. Vol. I, 3), Conacher (Euripidean drama: myth, theme and structure. Toronto/ London: University of Toronto Press, 1967), de Romilly (L'évolution du pathétique, d'Eschyle à Euripide. Paris: PUF, 1971/ Le temps dans la tragédie grecque. Paris: Vrin, 1974), Schaerer (L'homme antique et la structure du monde intérieur. Paris: Payot, 1958), Grube (The drama of Euripides. London: Methuen, 1941), Kamerbeek [Mythe et réalité dans l'oeuvre d'Euripide. En: Diller, H.; Kamerbeek, J. C.; Lesky, A.; Martin, V.; Rivier, A.; Winnington-Ingram, R. P.; Zuntz, G. (orgs.). Euripide. Fondation Hardt pourl'étude del'antiquité classique. Genève: Fondation Hardt, 1960. Tome VI, p. 3-25], Oranje (Euripides' "Bacchae". Their play and its audience. Leiden: Brill, 1984), Tovar (Eurípides. Tragedias. Las Bacantes - Hécuba. Barcelona: Alma Mater, 1960. Vol. II), Webster (The tragedies of Euripides. London: Methuen, 1967) y Winnington-Ingram (Euripides and Dionisus. Cambridge: Cambridge University Press, 1948).

${ }^{4}$ Hemos discutido la cuestión en Nápoli (Espectáculo y teatralidad en Bacantes de Eurípides. Humanitas. Coimbra, vol. LXII, p. 57-81, 2010).

${ }^{5}$ Cf. Segal, E. Euripides: poet of paradox. En: (org.). Oxford readings in Greek tragedy. Oxford: Oxford University Press, 1991, p. 244-253. 
sufrimiento. ${ }^{6}$ Así, le pregunta entonces el dios travestido en profeta de su propio culto a Penteo:

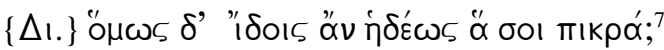

No puede dejar de destacarse que el verso resulta profundamente significativo, y su estructura compositiva muestra la importancia asignada por el poeta. A través de la unión de una sinestesia con un oxímoron, en la que se conjugan sensaciones visuales (verías) y gustativas contrastadas (dulcemente-lo amargo), se nos presenta de manera abrupta el problema de la paradoja trágica. La pregunta del dios nos pone en presencia de la cuestión de las emociones. El dios le pregunta a Penteo acerca del tipo de participación que el rey de Tebas espera recibir de la representación del culto dionisíaco; esta pregunta sirve de espejo a la participación que el espectador en general obtiene de la representación dramática. La relación entre el espectador (representado aquí por Penteo) y el espectáculo contemplado (su observación del culto dionisíaco) es un símbolo de la relación entre el espectador teatral y la obra representada. Creemos que la discusión acerca de la naturaleza de esta relación está en el centro del interés de la tragedia.

Sin embargo, debemos comenzar con el análisis de los aspectos míticos y rituales de la tragedia, que constituye, de alguna manera, el espectáculo que contemplará primero el público (con la danza y el canto de la párodos), luego el mensajero que trae la narración de este culto y finalmente Penteo, cuando travestido en bacante asista a la representación del monte Citerón. Como es bien sabido, la tragedia griega tuvo oscuros orígenes vinculados con las celebraciones religiosas comunales dedicadas a Dioniso, el dios tracio, de cuyos rituales y misterios toma su forma. ${ }^{8}$ Sin embargo, el mito dionisíaco parece estar ausente de todas las representaciones trágicas anteriores.

Es por ello que la cuestión de la vinculación de la tragedia griega con el culto de este dios permanecerá siempre muy debatida, hasta convertir en proverbial el refrán de nada que ver con Dioniso para referirse

\footnotetext{
${ }^{6}$ Cf. Segal, C. El espectador y el oyente. En: Vernant, J.-P. et alii (orgs.). El hombre griego. Trad. de Antonio Bravo García. Madrid: Alianza Editorial, 1993, p. 211-246.

7 “¿Verías con gusto lo que es amargo para ti?? Todas las traducciones del texto griego son nuestras.

${ }^{8}$ Cf., entre la copiosa bibliografía, Rodríguez-Adrados, F. Fiesta, comedia y tragedia. Madrid: Alianza Editorial, 1983.
} 
a esta relación. ${ }^{9}$ Sin embargo, un análisis más detenido nos puede mostrar una de las vías en las que el culto del dios del teatro y de la propia representación escénica ha sido visto en la antigüedad. Según Aristóteles, la representación o imitación de las acciones (mímesis) del héroe trágico, sus errores o fragilidad (hamartía) se conjugan, provocando emociones purificadoras de piedad y de terror que constituyen la kátharsis (Poética 335-332 a. C.). No obstante, no poseemos ninguna representación histórica ni de esta vinculación entre tragedia y culto dionisíaco, ni de las emociones catárticas provocadas sobre los espectadores. Bacantes, última tragedia del período clásico, es, a su vez, la única de tema dionisíaco. Por ello, su interpretación podrá ser un punto de partida adecuado para plantear los problemas generales que la lectura del género despierta.

En la párodos de Bacantes, ${ }^{10}$ el coro de mujeres asiáticas explica lo que constituye el fundamento mítico de sus creencias y, al mismo tiempo, describe el tipo de rituales que practican. ${ }^{11}$ A partir de esta doble explicación por parte del coro de bacantes asiáticas en su primer ingreso a escena, procuraremos analizar su canto en una doble referencia: respecto de la consideración de estos rituales como un ejemplo de los cultos que dieron origen al teatro clásico y respecto de la interpretación general de la tragedia como una reflexión sobre el quehacer teatral por parte de su autor.

En Homero, hay dos escenas que representan la intimidad deseada entre el ejecutor de la performance épica con su público, y los efectos que espera producir: se trata del momento en que Aquiles, en el primer canto de Ilíada, le narra a la diosa Tetis, su madre, lo que le ha ocurrido con Agamenón. En el canto 23 de Odisea, es Odiseo quien le hace a su recientemente recuperada esposa Penélope un resumen de sus aventuras. En cada caso, el oyente comprometido emocionalmente con aquello que escucha se conmueve hasta las lágrimas con el relato. La relación narradoroyente, en el propio relato, espeja la esperada relación rapsoda-oyente en el marco de la ejecución épica. Creemos que en Bacantes se produce una serie muy amplia de relatos y representaciones acerca del efecto que

\footnotetext{
${ }^{9}$ Cf. C. Segal (Interpreting Greek tragedy. Myth, poetry, text. Ithaca/ London: Cornell University Press, 1986), J. Winkler y F. Zeitlin (Nothing to do with Dionysos? Athenian drama in its social context. New Jersey: Princeton, 1992).

${ }^{10}$ Cf. García Gual, C. Dioniso en la tragedia. Helmántica. Salamanca, vol. XXVI, p. 185-198, 1975.

${ }^{11}$ Cf. Seaford, G. Dionysiac drama and the dionysiac mysteries. CQ. Oxford, vol. XXXI, p. 252-275, 1981.
} 
produce la contemplación de un espectáculo, de manera de espejar también el efecto que produce la representación teatral en el espectador.

En el comienzo del tercer episodio, un mensajero le cuenta a Penteo la manera en que ha visto a las ménades tebanas cumpliendo sus ritos en la montaña (v. 677-774), con la doble instancia de las bacantes en calma y las bacantes en frenesí por la intromisión de un extraño al culto. El relato del segundo mensajero (v. 1043-1153) narra la manera en que ha contemplado el momento en que las ménades en calma descubren la intromisión de Penteo y, atacadas de una furia sobrenatural, destruyen en rito báquico a aquel que transgredió las prohibiciones. En ambos casos, los mensajeros han sido espectadores de un espectáculo de dos caras, una plácida y dichosa y la otra espeluznante. Sin embargo, poco se nos dice de sus emociones. De todas maneras, ellos narran lo que han visto, al modo del aedo de la épica, pero el público del teatro no puede contemplar sus reacciones inmediatas ante la contemplación del espectáculo, que ocurre siempre en un espacio alejado del espacio escénico.

Sin embargo, la narración de la relación espectador-espectáculo que traen sobre la escena estos mensajeros tiene una función de importancia: presenta a los espectadores teatrales la cuestión de la reflexión acerca de esta relación espectador-espectáculo. Sobre el escenario del teatro hay, no obstante, un momento en el que el público mismo es espectador de las reacciones de un personaje teatral ante un espectáculo que contempla a la vista de los propios espectadores: se trata de Penteo, que contempla y reacciona ante la ejecución de un segmento del culto dionisíaco por parte de las mujeres asiáticas sobre el escenario, en el momento de celebrar el himno dionisíaco que constituye la párodos.

El punto de partida de nuestro análisis lo constituye entonces el canto inicial del coro. ${ }^{12}$ En el prólogo de la tragedia (v. 1-63), un Dioniso metamorfoseado en profeta de su propio culto preanuncia lo que ocurrirá sobre la escena, y establece el objetivo de su castigo a Penteo (v. 47-48):

\footnotetext{
${ }^{12}$ Sobre los coros en Eurípides puede verse Parry (The lyric poems of Greek tragedy. Toronto/ Sarasota: Samuel Stevens, 1978, p. 145-225) y, sobre la párodos de Bacantes, Festugière [Les mystères de Dionysos. En: . (org.). Études de religion grecque et héllenistique. Paris: Vrin, 1972, p. 13-63].
} 


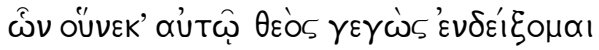

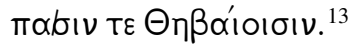

Para cumplir con este cometido cuenta con la ayuda de un grupo de mujeres que lo siguen desde Asia: son las ménades asiáticas, que han abandonado el Tmolo, en Lidia, para acompañar al profeta que anuncia la nueva religión de Dioniso. Cuando este coro de mujeres asiáticas ingresa a escena, su canto representa una clave importantísima para interpretar la tragedia y para comprender algunos aspectos del culto dionisíaco del cual surgió el propio teatro.

La párodos se dividen en un breve preludio (v. 64-72), dos pares de largas estrofas y antiestrofas y un largo epodo. Lo primero que hacen las mujeres en el preludio es pedir el silencio sagrado previo a la celebración cultual (v. 70):



El teatro mismo, por tanto, como espacio de la representación escénica que incluye a los actores y a los espectadores, se convierte entonces en el lugar en donde el ritual no sólo se explica, sino que se ejecuta, se actualiza. Los dos versos finales de esta introducción anuncian lo que veremos y escucharemos a continuación (v. 71-72):

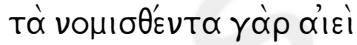

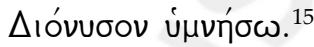

Es decir, el himno que las mujeres asiáticas nos permitirán escuchar y ver (ya que la indumentaria del culto así como la danza que acompaña este canto forman una parte inescindible de él) constituye una parte del conjunto de actos que conforman el ritual acostumbrado del culto dionisíaco. El espacio de la representación teatral se ha convertido en el espacio de la representación del culto. Los personajes de la representación

\footnotetext{
13 "A causa de estas cosas le mostraré a él y a todos los tebanos que he nacido dios". Sobre el castigo que le corresponde a quien ha desafiado a un dios, cf. Ieranó, G. Forme della necessità nelle "Baccanti" di Euripide. Dioniso. Palermo, vol. LXI, p. 45-60, 1991.

14 "Que todos mantengan su boca en un silencio sagrado".

15 "Pues siempre cantaré un himno a Dioniso, cumpliendo con los ritos acostumbrados".
} 
teatral y los espectadores se convierten, de esta manera, al mismo tiempo, en testigos y participantes de una ceremonia de culto.

La primera estrofa comienza con la invocación $\omega \hat{~} \mu \alpha k \alpha \rho$, ő $\sigma$ tıs (v. 73), que introduce el tema de la bienaventuranza. Bienaventurado entre los mortales es aquel que desarrolla una triple sabiduría: conoce los misterios de los dioses (v. 73), santifica su vida (v. 74) y consagra su alma en las celebraciones de los thíasos dionisíacos (v. 75-76). ${ }^{16}$ Esta sabiduría (que es mucho más que el mero conocimiento intelectual) va a ser contrastada rotundamente con la ciencia sofística de Penteo, capaz de razonar pero incapaz de comprender el destino final de sus decisiones. El contraste entre estas dos sabidurías no podría ser más significativo.

A partir de este momento, el coro desarrolla cada una de estas tres vías de la sabiduría dionisíaca: el conocimiento de los misterios está constituido por el mito dionisíaco, desarrollado en el resto de la estrofa primera y en toda la antiestrofa primera. ${ }^{17}$ El relato viene presentado, como es usual en la estructura de los himnos, por la invocación a la divinidad, y la subordinada relativa que, junto con el adverbio temporal, introduce la narración de los hechos anteriores que justifican la fe y las conductas actuales (v. 83-92):

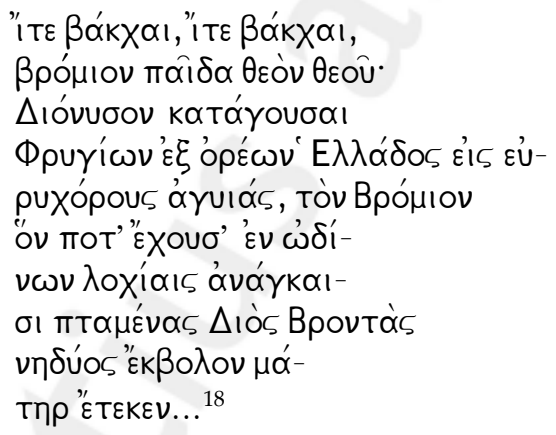

\footnotetext{
${ }^{16}$ En la antigüedad se denominaba Thíasos a la compañía o cofradía que se encargaba de celebrar las fiestas en honor de una divinidad y que formaba el ruidoso tropel de personajes cuya procesión acompañaba al dios en sus días de júbilo (cf. RodríguezLópez, M. I. El poder del mar: el "Thíasos marino". Espacio, tiempo y forma. Madrid, vol. XI, p. 159-184, 1998).

${ }^{17}$ Cf. Olson, S. D. Traditional forms and euripidean adaptation: the hero pattern in "Bacchae". CW. Pittsburgh, vol. LXXXIII, n. 1, p. 25-28, 1989.

18 "iVenid, bacantes! iVenid, Bacantes!, devolviendo a Bromios, el dios hijo de un dios, a Dioniso, desde las montañas de los frigios hacia las inmensas vías de la Hélade, a Bromios, a quien alguna vez parió su madre después de sufrir los dolores del alumbramiento, expulsado prematuramente por el trueno de Zeus...”
} 
El mito es muy sencillo: Semele, su madre humana, con los dolores de parto anticipados por el trueno de Zeus, el padre divino, lo dio a luz y murió en el mismo momento. Su padre Zeus, por tanto, recoge al recién nacido y a escondidas de Hera lo guarda en su muslo, cosiéndolo con agujas de oro. Una vez llegada la hora, parió a un dios con cuernos de toro y lo coronó con serpientes. Es importante reconocer que la parte mítica de esta sabiduría se limita a la cuestión central, ya anticipada por el propio Dioniso en el prólogo y refrendada en el éxodo de la tragedia: el hijo de Semele es al mismo tiempo el hijo de Zeus. Se trata simplemente de reconocer la divinidad de Dioniso. En ello consisten los misterios y los conocimientos requeridos a los bienaventurados.

La segunda estrofa, con su correspondiente antiestrofa, desarrolla otro aspecto de la sabiduría dionisíaca: aquel de quien es capaz de llevar una vida santa. Este aspecto de la sabiduría dionisíaca tiene vinculación con la participación general en los cultos del dios: los ramos de encina o de abeto que deben coronar la cabellera del celebrante, las pieles moteadas de cervatillo con las que debe cubrirse, el tirso en la mano que acompaña la danza alrededor de toda la tierra que lleva hasta el monte, el ámbito agreste que contrasta con el de la civilización, resaltado además por la mención del abandono por parte de las mujeres de las prácticas propias de su posición dentro de la sociedad. Pero ello no alcanza. Junto con esto, deben acompañar a las ménades los instrumentos musicales: el pandero que inventaron los coribantes y la flauta frigia que, junto con el canto y con la danza, constituyen el momento acostumbrado del culto dionisíaco: es interesante notar el aspecto mimético de estas celebraciones, ya que el coro menciona de manera específica que se convierte en Bromio cualquiera que comande la comitiva en éxtasis. De esta manera, podemos ver una actualización del tipo de cantos de los coros dionisíacos que, según Aristóteles en su Poética, están en el origen de la tragedia griega. Aquel que participa en estas celebraciones alcanza la makaría anunciada por el coro en el comienzo de la primera estrofa.

Pero esto no es todo. Hay todavía un paso más. El epodo introduce

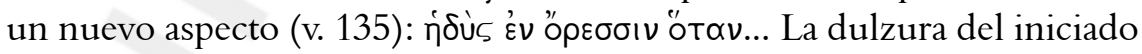
alude a un paso posterior, a un más allá de la sabiduría dionisíaca, que está constituido por este tercer aspecto, aquel de quien consagra su alma en las celebraciones de los thíasos. Este aspecto mistérico de la celebración dionisíaca parece estar constituido exclusivamente por un tipo de culto en donde la oreibasía, el esparagmós y la omofagia constituyen los tres momentos significativos del culto. Pero la brutalidad y la carencia de civilización del culto (celebrado por mujeres que han 
abandonado a sus maridos y sus obligaciones femeniles, fuera de la ciudad - en el monte - y fuera de la luz - de noche) contrasta con las bondades que recibe el celebrante (v. 142-143):

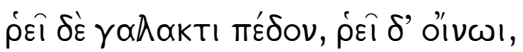

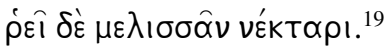

El celebrante es capaz de hacer manar leche, vino y miel del suelo. Se trata de un milagro ahora celebrado pero que, en las posteriores narraciones de los mensajeros, el público podrá verificar en su auténtica realización. Como un potro que pace junto a su madre, la bacante que participa de las danzas báquicas es capaz de alcanzar una integración cósmica con la naturaleza de la que la civilización está al margen. ${ }^{20}$

Penteo, a lo largo de la tragedia, es testigo privilegiado de estas celebraciones. Escucha a las mujeres del coro, dialoga con el profeta de su culto, intenta apresarlo y fracasa porque los milagros del palacio liberan inmediatamente al profeta, tal como lo había anticipado. El culto que se representa sobre el escenario y del cual Penteo y el público son testigos y partícipes $^{21}$ tiene dos aspectos: la calma y la felicidad de las ménades integradas a la naturaleza, la furia destructiva en contra de aquel que se atreve a desafiar las prohibiciones sagradas. ${ }^{22}$ La representación de la tragedia es una actualización de este doble aspecto del culto dionisíaco y, al mismo tiempo, una actualización del efecto que la tragedia produce en aquellos que participan de su representación.

Este punto es importante para una reinterpretación de la obra. Eurípides contrasta el resultado esperado por la contemplación consumada por Penteo, ávido siempre de nuevos espectáculos, y la nula reacción ante ellos. No hay, como en el caso de la épica, ni compromiso

\footnotetext{
19 "Y la tierra mana leche, y mana vino, y mana el néctar de las abejas".

${ }^{20}$ Cf. Gold, B. K. Eưkoøuía in Euripides' "Bacchae". AJPh. Baltimore, vol. XCVIII, p. 3-15, 1977.

${ }^{21}$ Cf. Seaford, R. Pentheus' vision: "Bacchae" 918-22. CQ. Oxford, vol. XXXVII, p. 76-78, 1987.

${ }^{22}$ Sobre la vinculación de la furia destructiva de las ménades con la sexualidad femenina fuera de control puede consultarse C. Segal [The menace of Dionysus: sex roles and reversals in Euripides' "Bacchae". En: Peradotto, J.; Sullivan, J. (orgs.). Women in the ancient world. Albany: State University of New York Press, 1984, p. 195212, 1984] y F. Zeitlin (Cultic models of the female: rites of Dionysus and Demeter. Arethusa. Baltimore, vol.XV, n. 1-2, p. 129-157, 1982).
} 
ni efecto catártico. Penteo ve y sólo quiere ver más, hasta que se atreve a travestirse en una bacante él mismo para poder observar más de cerca a las mujeres en sus cultos. ${ }^{23}$ El mundo entero es un teatro, ${ }^{24}$ y el desafío que Eurípides plantea a sus espectadores consiste justamente en este llamado a una reacción diferente a la de Penteo, a una reacción que fuera capaz de devolverle al mundo la unidad de sentido que, entonces como ahora, parecía entrar en conflicto para estos seres que confían solamente en la fuerza de la razón.

\section{Bibliografía}

ARNOTT, P. Greek scenic conventions in the VC. Oxford: Clarendon Press, 1962.

CONACHER, D. J. Euripidean drama: $m y$ th, theme and structure. Toronto/ London: University of Toronto Press, 1967.

DETIENNE, M. La muerte de Dionisos. Madrid: Taurus, 1983.

DODDS, E. R. The Bacchae of Euripides. Oxford: Clarendon Press, 1968.

FESTUGIÈRE, J. De l'essence de la tragédie grecque. Paris: Aubier-Montaigne, 1969.

. La signification religieuse de la parodos des «Bacchantes». En:

(org.). Études de religion grecque et héllenistique. Paris: Vrin, 1972, p. 66-80.

. Les mystères de Dionysos. En: . (org.). Études de religion grecque et héllenistique. Paris: Vrin, 1972, p.13-63.

. Ce que Tito-Livio nous apprend sur les mystères de Dionysos. En:

(org.). Études de religion grecque et hellenistique. Paris: Vrin, 1972, p. 89-109.

GARCÍA GUAL, C. Dioniso en la tragedia. Helmántica. Salamanca, vol. XXVI, p. 185-198, 1975.

GREGOIRE, H. Euripide. Les Bacchantes. Paris: Les Belles Lettres, 1961. Tome VI.

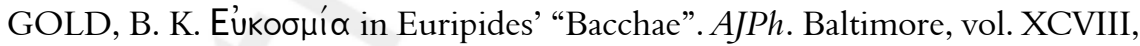
p. 3-15, 1977.

GREENWOOD, L. Aspects of euripidean tragedy. New York: Cambridge at the University Press, 1972.

GRUBE, G. The drama of Euripides. London: Methuen, 1941.

Cf. Kalke, C. The making of a Thyrsus: the transformation of Pentheus in Euripides' "Bacchae". AJPh. Baltimore, vol. CVI, p. 409-426, 1985.

${ }^{24}$ Cf. Whitehorne, J. The dead as spectacle in Euripides" "Bacchae" and "Supplices". Hermes. Stuttgart, vol. CXIV, p. 59-72, 1986. 
IERANÓ, G. Forme della necessità nelle "Baccanti” di Euripide. Dioniso. Palermo, vol. LXI, p. 45-60, 1991.

JAEGER, W. Paideia. Trad. de Joaquín Xiral. México: Fondo de Cultura Económica, 1967.

JEANMAIRE, H. Dionysos. Histoire du Culte de Bacchus. Paris: Payot, 1951.

KALKE, C. The making of a Thyrsus: the transformation of Pentheus in Euripides' "Bacchae".AJPh. Baltimore, vol. CVI, p. 409-426, 1985.

KAMERBEEK, J. C. Mythe et réalité dans l'oeuvre d'Euripide. En: Diller, H.; Kamerbeek, J. C.; Lesky, A.; Martin, V.; Rivier, A.; Winnington-Ingram, R. P.; Zuntz, G. (orgs.). Euripide. Fondation Hardt pourl'étude de l'antiquité classique. Genève: Fondation Hardt, 1960. Tome VI, p. 3-25.

KAUFFMANN, W. Tragedia y filosofía. Barcelona: Seix Barral, 1978.

KIRK, S. The "Bacchae” of Euripides. Prentice Hall: Englewood Cliffs, 1970.

LACROIX, M. Les Bacchantes d'Euripide. Paris: Les Belles Lettres, 1976.

LASSO DE LA VEGA, J. Notas críticas a Eurípides, "Bacantes”. Cuadernos de Filología Clásica. Madrid, NY22, p. 9-31, 1989.

LESKY, A. Historia de la literatura griega. Madrid: Gredos, 1976.

LÓPEZ PUERTAS, G. El mensaje liberador de Dioniso en las "Bacantes" de Eurípides. Espéculo. Revista de estudios literarios. Madrid, n. 28, 2004. < http:// www.ucm.es/info/especulo/numero28/dioniso.html>

MURRAY, G. Eurípides y su tiempo. México: Fondo de Cultura Económica, 1966 (1913).

NÁPOLI, J. T. Espectáculo y teatralidad en "Bacantes" de Eurípides. Humanitas. Coimbra, vol. LXII, p. 57-81, 2010.

NESTLE, W.Euripides. Der Dichter der griechischen Aufklärung. Stuttgart: W. Kohlhammer, 1901.

.Vn Mythos zum Logos. Die Selbstentfaltung des griechischen Denkens von Homer bis aufdie Sophistik und Socrates, Stuttgart: Scientia, 1941.

. Historia del espíritu griego. Barcelona: Ariel, 1987.

NORWOOD, G. The riddle of the Bacchae. London: Victoria University of Manchester, 1908.

. Greek Tragedy. London: Methuen, 1920.

. Essays on Euripidean drama. Berkeley: University of California Press, 1954.

OLSON, S. D. Traditional forms and euripidean adaptation: the hero pattern in "Bacchae". CW. Pittsburgh, vol. LXXXIII, n. 1, p. 25-28, 1989.

ORANJE, H. Euripides' “Bacchae”. Their play and its audience. Leiden: Brill, 1984.

PARRY, H. The lyric poems of Greek tragedy. Toronto/ Sarasota: Samuel Stevens, 1978.

RIVIER, A. Essai surle tragique d'Euripide. Lausanne: Rouge, 1944. 
RIVIER, A. L'élément démonique chez Euripide jusqu'en 428. En: Diller, H.; Kamerbeek, J. C.; Lesky, A.; Martin, V.; Rivier, A.; Winnington-Ingram, R. P.; Zuntz, G. (orgs.). Euripide. Fondation Hardt pour l'étude de l'antiquité classique. Geneve: Fondation Hardt, 1960. Tome VI, p. 43-86.

RODRÍGUEZ-ADRADOS. F. Fiesta, comedia y tragedia. Madrid: Alianza Universidad, 1983.

RODRÍGUEZ-LÓPEZ, M. I. El poder del mar: el "Thíasos marino". Espacio, tiempo y forma. Madrid, vol. XI, p. 159-184, 1998.

de ROMILLY, J. L'évolution du pathétique, d'Eschyle à Euripide. Paris: PUF, 1971. . Le temps dans la tragédie grecque. Paris: Vrin, 1974.

ROUX, J. Euripide. Les Bacchantes. Introduction, texte et traduction, commentaire. Paris: Les Belles Lettres, 1970 y 1972.

SCHAERER, A. L'homme antique et la structure du monde intérieur. Paris: Payot, 1958.

SCHMIDT, J. Geschichte der griechischen Literatur. München: Beck, 1940. Vol. I, 3.

SEAFORD, R. Dionysiac drama and the dionysiac mysteries. CQ. Oxford, vol. XXXI, p. 252-275, 1981.

1987.

. Pentheus' vision: "Bacchae” 918-22. CQ. Oxford, vol. XXXVII, p. 76-78,

SEGAL, C. El espectador y el oyente. En: VERNANT, J.-P. et alii. (orgs.). El hombre griego. Trad. de Antonio Bravo García. Madrid: Alianza Editorial, 1993, p. 211-246.

. The menace of Dionysus: sex roles and reversals in Euripides' "Bacchae". En: PERADOTTO, J.; SULLIVAN, J. (orgs.). Women in the ancient world. Albany: State University of New York Press, 1984, p. 195-212. Press, 1986.

Interpreting Greek tragedy. Myth, poetry, text. Ithaca/ London: Cornell University

. Euripides: poet of paradox. En: . (org.). Oxford readings in Greek tragedy. Oxford: Oxford University Press, 1991, p. 244-253.

TOVAR, A. Eurípides. Tragedias. Las Bacantes - Hécuba. Barcelona: Alma Mater, 1960. Vol. II.

VERNANT, J.-P. et alii (orgs.). El hombre griego. Trad. de Pedro Bádenas de la Peña, Antonio Bravo García y José Antonio Ochoa Anadón. Madrid: Alianza Editorial, 1993.

VERRALL, A. Euripides, the Rationalist. A study in the history of art and religion. Cambridge: Cambridge University Press, 1895.

.The Bacchants of Euripides and other essays. Cambridge: Cambridge University Press, 1910.

WEBSTER, T. B. L. The tragedies of Euripides. London: Methuen, 1967.

WHITEHORNE, J. The dead as spectacle in Euripides' "Bacchae" and "Supplices". Hermes. Stuttgart, vol. CXIV, p. 59-72, 1986. 
WINKLER, J.; ZEITLIN, F. (orgs.). Nothing to do with Dionysos? Athenian drama in its social context. New Jersey: Princeton, 1992.

WINNINGTON-INGRAM, R. Euripides and Dionisus. Cambridge: Cambridge University Press, 1948.

ZEITLIN, F. Cultic models of the female: rites of Dionysus and Demeter. Arethusa. Baltimore, vol. XV, n. 1-2, p. 129-157, 1982. 